\title{
What Does it Mean to Design? A Qualitative Investigation of Design Professionals' Experiences
}

\author{
Shanna R. Dalya , Robin S. Adams, And George M. Bodner \\ University of Michigan ${ }^{a}$, Purdue University
}

\begin{abstract}
BACKGROUND
Design is essential to the engineering profession and plays a crucial role in preparation for future practice. Research investigating variations of how professional designers experience, give meaning to, and approach design can inform the ways we characterize, assess, and facilitate design learning. This may also have significant implications for preparing future engineering professionals to collaborate within and across disciplines.
\end{abstract}

\section{PuRPose (HyPOTHESIS)}

The goal of the study was to reveal and investigate critical differences in how designers from within and outside of engineering disciplines understand what it means to design, and how those understandings are evident in their approaches to and progression through design work.

\section{DESIGN/MethoD}

A qualitative research approach called phenomenography was used to investigate critical variations in how individuals experience and understand design. Twenty practicing designers were interviewed regarding their design experiences, how they approach design, and the ways they understand design.

\section{CONCLUSIONS}

Six qualitatively distinct lenses on how individuals across disciplines experience and come to understand design emerged, comprising a phenomenographic "outcome space." These include design as (1) evidencebased decision-making, (2) organized translation, (3) personal synthesis, (4) intentional progression, (5) directed creative exploration, and (6) freedom. Theoretical implications include an understanding of how design skills and knowledge come together to form a design approach, while practical implications emphasize structuring variation-based reflection, which can facilitate common ground as a result of recognizing different "design lenses."

\section{KEYWORDS}

design cognition, design education, phenomenography

\section{INTRODUCTION AND BACKGROUND}

Design is often defined as synonymous with what engineers "do." Early accounts from professional engineering organizations included design as a key aspect in their definitions of engineering: "the creative application of scientific principles to design or develop structures, machines, apparatus, or manufacturing processes, or works utilizing them singly or in combination..." (Engineers' Council for Professional Development, 1947). More recently, a definition of engineering from the National Academy of Engineering has been proposed as "design under constraints" (National Academy of Engineering, n.d.). According to the National 
Academy of Engineering (NAE) (2004), "Engineers in 2020, like engineers of yesterday and today, will possess strong analytical skills. At its core, engineering employs principles of science, mathematics, and domains of discovery and design to a particular challenge and for a practical purpose." Just as accreditation policies for engineering programs emphasize an ability to design as an outcome and measure of professional preparation (ABET Board of Directors, 2007), statements on the future of engineering emphasize the need for engineering graduates to design across disciplines (Committee on the Engineer of 2020, 2004; Duderstadt, 2008; Sheppard, Macatanga, Colby \& Sullivan, 2009). Understanding differences in how designers approach design can inform engineering education and help novice designers become more expert-like and more successful in collaborative and cross-disciplinary endeavors.

A significant challenge for engineering education is preparing students and practitioners for the changing dynamics of design practice (NAE, 2004). While there are rich sources of evidence on design skills and knowledge, the ways these tie together and guide a designer's approach to and conception of design, what we call a "design lens," is unclear. Studies on what designers know about design are necessary to create crucial bridges between what designers do and why designers do what they do. Studies to address this gap would need to explore the situated nature of design knowledge - rather than lists of decontextualized skills and knowledge — and purposefully investigate the ways people experience design and what they understand about design through these experiences. These kinds of studies are a relatively recent trend in design research (Adams, Forin, Srinivasan, \& Mann 2010; Kabo \& Baillie, 2009; Mann, 2007; Reid \& Solomonides, 2007; Zoltowski, Oakes, \& Cardella, 2012). The existing body of knowledge has focused more on how designers design and the importance of design strategies in the phases of a design process for producing quality solutions (Adams, Turns, \& Atman, 2003; Atman, Chimka, Bursic, \& Nachtmann, 1999; Atman et al., 2007; Cross, 2001; Lawson \& Dorst, 2009; Newstetter \& McCracken, 2001; Visser, 2006). Less attention has been given to how designers (from novices to practicing professionals) conceive of, experience, and approach design as a type of activity (Mosborg, et al., 2005; Newstetter \& McCracken, 2001) and how beliefs about design change over time such as a move towards understanding the importance of problem formulation activities (Atman, Kilgore, \& Mckenna , 2008) or iteration (Adams \& Fralick, 2010). Investigating the qualitatively different ways people experience design can make visible critical variations in how people understand design, which in turn would be a significant contribution towards building a theory of design learning (Marton \& Tsui, 2004) and an associated theory of design education.

Design experiences play a prominent role in the first and capstone years of undergraduate programs (Dym, Agogino, Eris, Frey, \& Liefer, 2005) as well as K-12 engineering education (Cunningham, Knight, Carlsen, \& Kelly, 2007; Douglas, Iverson, \& Kalyandurg, 2004). The approach to design taken by designers from seemingly different disciplines may have many similarities, and designers educated in the same discipline may have different lenses on what it means to design. As there is no one right way to approach design, in engineering education, it may be most valuable to focus on the "big ideas" of design thinking (Adams et al., 2003; Cross, 2001; Nelson \& Stolterman, 2003) and lay the groundwork for students to fluidly transfer design knowledge and skills to different kinds of situations. Focusing on why people design the way they do and how design knowledge and strategies are synthesized by a designer to support skillful design performance may play a crucial role in helping engineering students move from a naïve view of design as a linear sequential process to a more expert-like view of design as non-linear and iterative. Studies that investigate how 
design is experienced across multiple contexts and disciplines may play a crucial role in articulating aspects of design knowledge that can directly contribute to design teaching in engineering education.

Understanding "design lenses" may play an important role in preparing engineering professionals around the globe to work in a world of continual change. These "engineers of 2020 " will need to be agile, resilient, flexible, and able to frame problems in socio-technical contexts and collaborate effectively with multiple stakeholders (NAE, 2004). They will need to address grand challenges, cross-disciplinary and complex problems of global significance that require groups of people from diverse disciplines and perspectives coming together to define what is viable, desirable, and feasible (Brown, 2009). For collaborations in these problem spaces, if a team member says "let's use the design process to manage this project" or "the most important thing in design is to find the triple-bottom line," one outcome is that the team may discover (perhaps too late) that while they may have been engaged in collaborative design, they may not have a shared understanding of design. Therefore, a major stumbling block to cross-disciplinary collaboration and innovation will require understanding variations in the ways people experience and make meaning around "design." Even designers engaging in collaboration within the same discipline are likely to have varying perspectives on what it means to design, and therefore, varying approaches to design work. They will need strategies to manage clashes in perspective in order to transition from a "storming" phase to "norming" and "performing" phases (see Tuckman's (1965) stages of group development). Enabling this kind of common ground may facilitate innovation at the interface between disciplines (Clark \& Brennan, 1991); an inability to perceive and leverage different views on design may restrict innovation (Committee on the Engineer of 2020 Phase I, 2004; Committee on Facilitating Interdisciplinary Research et al., 2005).

Finally, the knowledge generated by traditional engineering design research does not typically take into account the understanding and experience of the practice it seeks to examine. While the perspectives students bring to design are important, they do not necessarily reflect the views of practicing professionals who are actively involved in design on a regular basis. Focusing on professional practice reveals not only design knowledge and skills, but "also entails the development of professional ways of being" (Dall'Alba, 2004, 2005 , 2009). Studies that characterize the critical variations in design experiences, meanings, and approaches emphasized by professional designers can guide the development of design curricula by suggesting learning targets and instruments to assess learning in relation to these targets.

The goal of the study presented in this paper was to understand design professionals' meanings and critical aspects associated with their design experiences by probing the following guiding research question: What are the qualitatively different ways practicing designers from a variety of disciplines experience design? The idea of looking for distinct variations in how professionals experience and conceive of design is grounded in foundational concepts of phenomenography and variation theory. Specifically, people perceive their experiences with the same phenomenon (design in this case) in different ways because they distinguish different critical features of that phenomenon (Bowden \& Marton, 1998; Marton \& Booth, 1997). A study of this nature is productive because it helps to illustrate the scope of how people relate to the activity of design, grounded in in-depth, contextualized experiences.

In the following sections we describe the frameworks that situate the study and guided the research design, and then present findings on six qualitatively different ways design is experienced and understood. The findings are discussed in terms of their unique contributions to: (1) identifying features of general design knowing and thinking that map across 
disciplines and can be used to guide engineering design education, (2) describing what designers come to understand through their experiences and how they approach these situations that may enable transfer of skills and knowledge from one situation to another, and (3) articulating features of qualitatively different ways of experiencing design that reveal differences in awareness that may facilitate or hinder creating common ground in collaborative work around engineering grand challenges.

\section{RESEARCH FraMEWORK}

The focus of this study was to understand critical features that professionals within and outside of engineering associate with their meanings of design. The goal was not to characterize disciplinary conceptions of design, but how individuals in a variety of disciplines distinguish critical features of their design work. In this section, we review design definitions, descriptions, and characteristics to support our premise that design activity occurs across many disciplines, and that while disciplinary perspective plays a role, similarities and differences in design lenses are highly dependent on context and prior experiences of the designer. This review also serves as a framework for the kinds of design aspects that may have emerged from the data as well as makes evident a research gap in understanding what designers do and why, specifically, how a designer's skills, knowledge, and experiences come together in a context to shape the designer's approach and progression through design work. The studies represent a synthesis that draws on research from general and discipline-specific studies of design and include: (1) features of situations (task environments) that trigger "designerly" ways of thinking (Cross, 2006), (2) perceptions of design as related to and distinct from problem solving, (3) social and contextual dynamics of these task environments, and 4) strategies and procedures that designers understand and use.

\section{Features of Design Situations}

To explore the ways in which professionals experience design, it is critical to establish the extent to which situations may be characterized as prototypical, or central, to design situations. Goel and Pirolli (1992) proposed and verified a framework for characterizing a domain-general perspective of design task environments. They utilized existing literature to identify twelve "significant invariants" of a design task environment and then tested this framework on a variety of situations that ranged from being "not central" to "central" to design activity. These invariants included: (1) incomplete or underspecified information; (2) non-negotiable (e.g., natural laws) and negotiable (e.g., social, political, legal, economic) constraints; (3) complexity in timeline and scale; (4) multiple parts; (5) contingently (not logically) interconnected parts; (6) the existence of better and worse (not right and wrong) answers; (7) outputs are specifications of the artifact based on inputs that include goals of artifact in the context in which it will function, including information about and from those who will use it; (8) partial feedback loops until the artifact is completed and used in the world; (9) high cost of errors; (10) independent functioning of the artifact from the designer; (11) artifact as separate from the specifications of it, i.e., they are not one in the same; and (12) temporal separation between specification and delivery.

As shown in Figure 1, a design situation that meets all 12 criteria would be considered "central" to design and therefore engages "designerly" ways of thinking. As the number of criteria met by a design situation decreases, the task is considered "less central" to design and more characteristic of non-design cases. Goel and Pirolli (1992) found that tasks from engineering and architecture closely resembled a design task environment, and that logic 


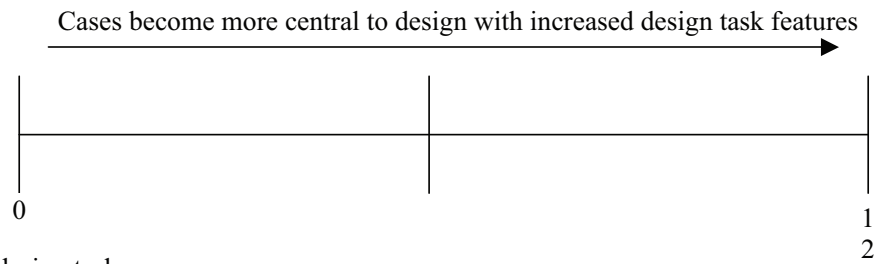

Non-design tasks

Number of Design Task Features Met By a Situation

Cases central to design

FIGURE 1. Representation of Goel and Pirolli's (1992) continuum of design centrality.

problems such as the Tower of Hanoi and cryptograms, while difficult, resembled non-design task environments. Drawing on Jonassen (2000), we may anticipate that task environments such as algorithmic problems, story problems, rule-using problems, and decisionmaking problems would be more towards the "non-design tasks" end of the continuum while diagnosis-solution, strategic performance, and case analysis problems may be more towards the "central to design" end of the continuum. As shown later, these 12 significant invariants were used to assess the extent to which a disciplinary professional is likely to experience design situations in their field and therefore be appropriate for inclusion in a study of design experiences.

\section{Perceptions of Design}

Professionals may distinguish their approach to design based on how they perceive the design situation. Simon (1969) developed a general theory of problem solving that included design as a unique "science of the artificial"; other design scholars clearly differentiated design from problem solving (Rittel \& Webber, 1973; Winograd, 1996). Nelson and Stolterman (2003), for example, argued that design is a "much richer concept than problem solving, because it shifts one's thought from focusing only on avoiding undesirable states, to focusing on intentional actions that lead to states of reality which are desirable and appropriate" (p. 17).

If a potential design problem is perceived as problem solving, a specific approach is likely to follow. Thomas and Carroll (1979) established that there was a unique way to go about design compared to other forms of problem solving, thus, if that same problem is viewed as a design problem, a problem with real context and real people, who have objective and subjective ideas about the qualities of good and bad designs, the task is likely to be approached differently.

A premise of our work was that not all tasks perceived as design tasks would be viewed and approached in the same way. Mosborg and Adams (2005) compared the design approaches of two practicing professional engineering designers. One engineer perceived a task of designing a fictitious playground as routine and therefore described an efficiency approach of minimizing the work of formulating the problem and using a "plausible" existing solution. The other perceived the task as novel and therefore described a divergent approach of exploring as many facets of the problem and solution space as possible. Thus, one way professionals may experience design is illustrated in the cognitive link between characteristics of a task and perception of the task. This perception of the task then influences thinking and engagement in that situation (Cross, 1995; Dorst, 2003; Goel \& Pirolli, 1992; Neely, 2007; Rittel \&Webber, 1973; Visser, 2006). 


\section{Social and Contextual Dynamics}

Professionals are likely to describe the social and contextual aspects of design as an essential aspect of the way they experience and make meaning of design situations. This is to be expected since design is inherently a social process (Bucciarelli, 1996). The complexity of design often requires a team with varying expertise to come together to produce an outcome that meets specified criteria. The collection of individuals involved in a design situation need to not only learn how to collaborate, but more importantly, recognize the potential clash and negotiation of perspectives that impact problem formulation, decomposition, and project management. Similarly, authentic design cannot be separated from its context. This context often means there are other people with ideas, values, and evaluation criteria of their own involved in the project, including a wide range of stakeholders from the general public, policymakers, and users. Contextual dynamics means there are considerations other than a "right" answer, and as such, impact designers' and stakeholders' ethical decisions, priorities, intuitive judgments, and considerations of users, culture, and tradition (Lawson \& Dorst, 2009).

\section{Design Procedures, Strategies, and Knowledge}

Representations of the act of designing or "process maps" may be used as lenses for making sense of the general way designers describe, experience, and organize how they go from "beginning" to "end" of a design task. User- and human-centered models, for example, focus design lenses on the needs and perspectives of the user throughout the design task (Vredenburg, 2003); a complex systems lens focuses on how solutions emerge from careful articulation of design intentions that integrate many systems perspectives (Nelson \& Stolterman, 2003). Typical engineering design process models include aspects such as identifying the need, defining and analyzing the problem, making decisions, detailing, and presenting and communicating a product (Dubberly, 2004; Eide, Jenison, Mashaw, \& Northup, 2002; Ertas \& Jones, 1996; French, 1985). Within these models there is considerable freedom to combine approaches, change perspectives, and make decisions to take different paths to an outcome when it seems wise to do so. Others break down process models (drawing on such disciplines as architecture, industrial design, town planning, and engineering) into iterative phases of analysis, synthesis, and evaluation (Lawson, 2006). Dubberly (2004) compiled a thorough set of design models and maps from across a variety of disciplines that illustrated while there may be discipline-specific approaches to design, there also appear to be general ideas shared across disciplinary-specific models.

Translating process maps into design strategies makes visible features of design knowledge, designerly ways of thinking, and design learning. Studies of designers have focused on such issues as problem formulation, solution generation, iteration, evaluation and verification of solutions, communication and negotiation, and innovation (Adams et al., 2003; Atman et al., 1999, 2007; Bucciarelli, 1996; Cardella, Atman, Turns, \& Adams, 2002; Cross, 2001; Jonassen, Strobel, \& Lee, 2006; Mehalik \& Schunn, 2006; Petre, 2003). They also focus on more general strategies such as the use of analogy (Ball, Ormerod, \& Morley, 2003; Christensen \& Schunn, 2007; Stacey, Eckert, \& Earl, 2009) and reflective practice (Adams et al., 2003; Schön, 1993; Valkenburg, 1998).

Studies by Newstetter and McCracken (2001), Mosborg et al. (2005), Atman et al. (2008), Adams and Fralick (2010), and Cardella et al. (2008) add to the knowledge base regarding what engineers understand about design and how those ideas change over time in relation to educational experiences, such as a move toward understanding the importance of problem formulation and iteration. As an example, Mosborg et al. (2005) studied 18 practicing engineering professionals' conceptions of design by having them draw their 
representation of design and talk aloud as they read through a model of design. Study findings suggest that participants, while varying in their disciplinary training (e.g., mechanical, electrical, industrial, and structural engineering), shared some common views of why design proceeds as a set of iterative strategies (such as a lack of information about the situation or interactions with clients) and why communication is a design strategy and not a "step" at the end of the process. Collectively this research highlights important differences in strategy knowledge, use across levels of design experience, and impact on the quality of solutions (Atman et al., 1999, 2007, 2008) in terms of framing and exploring the design situation, choosing, testing, and evaluating ideas, and learning through design (Crismond \& Adams, in review).

This previous research identified a variety of ways people understand and go about designing, which allowed us to anticipate how professionals from many disciplines may experience design and make meaning of their experiences, while not predicting the actual outcomes of this study. This literature also points to a lack of knowledge about how these pieces fit together in distinct ways to form designers' lenses on their work. In the following section, we describe the study design and link study decisions to aspects of this research framework.

\section{RESEARCHDESIGN}

\section{Phenomenography as a Research Approach}

Phenomenography is an interpretive qualitative research approach used to capture the variation that exists among differing understandings of the same particular aspect of the world and to reveal the critical components that comprise that variation (Bowden, 2000; Marton, 1986; Marton \& Booth, 1997). The phenomenographic approach guides work on understanding how subjects experience, give meaning to, and interact with an aspect of the world based on their own personal understanding of their relationship with that aspect of the world, thus the focus is the relationship between the individuals and the aspect of the world. Distinct differences exist in the ways people perceive their experiences; the goal of phenomenographic work is deep description of these variations, i.e., the differing ways of experiencing. Thus, phenomenographic analysis targets a collection of individual experiences (Åkerlind, 2005).

Researchers are using phenomenography to build a theory on how variations in awareness can distinguish features of surface and deep learning (Marton \& Tsui, 2004) and a theory of professional development that integrates knowing and being within an embodied understanding of professional practice (Dall'Alba, 2009). The theory of variations supports the idea that learners must be aware not only of their own approaches and conceptions, but also must understand the differences among their views and others' views in order to develop alternative views.

The results of a phenomenographic analysis reflect the collection of understandings, or categories of description, among a group of participants, not the individual meanings held by individual participants in the study. The categories of description, along with the relationships among the categories, are known as the outcome space of a phenomenography. As such, the value of using phenomenographic methods is the ability to create a landscape view that encompasses diverse perspectives that distinguish critical features of this landscape of awareness while simultaneously highlighting the relationship among these variations (such as moving from narrow to broad, external to internal, and surface to deep levels of awareness). This contrasts other research analysis methods, such as thematic analysis that focuses on similarities of conceptions or experiences, and case-based analysis that emphasizes individual subjects. 
In the presentation of the outcome space, reliability is made evident through the description of the process of analysis, including ways interpretations were controlled and checked throughout the process as well as by providing evidence in the form of data excerpts that support the categories of description and their relationships (Sandberg, 1997). As different researchers may develop different categories of description from the same data, evidence supporting the description of the outcome space makes visible what constitutes a category of description and how they were attained.

As with other qualitative approaches, phenomenographic results are not considered generalizable, but instead transferable to other contexts (for a discussion of qualitative methods in the context of engineering education research, see Leydens, Moskal, \& Pavelich, 2004; for a discussion of phenomenography in the context of engineering education research, see Case \& Light, 2011). Additionally, while the distribution of participants whose experiences comprise each category of description and the representation of the sample group to their larger populations cannot be generalized, the range of variation in the sample is expected to reflect the range of variation in the population (Marton \& Booth, 1997).

For this study, the particular aspect of the world investigated was "design," and the goal was to find the critical variations that existed among the meanings and reflections shared by design professionals. It is important to highlight that this phenomenographic investigation of design is different than an investigation of design in a novice-expert study framework. Both novice-expert studies and phenomenography can be used in education to identify learning trajectories, however, a novice-expert approach would highlight key differences in the conceptions and approaches of novices and experts with the target of one expert way as a goal for student achievement, while the phenomenographic approach in this work sought to unpack the variation in expert conceptions and approaches. In the following sections we describe our research methods as guided by a phenomenographic approach.

\section{Participants}

Participant selection, as guided by the phenomenographic approach, was a strategic effort to gain the largest diversity in participants' experiences possible within the aims of the study (Akerlind, 2005). Twenty professional designers served as participants, which is in the range of traditional sample sizes of phenomenographic studies (Trigwell, 2000). The primary criterion for selection was diversity in technical design area across two dimensions relevant to engineering contexts: within engineering disciplines (e.g., sub-disciplines of engineering such as mechanical engineering) and across design-related disciplines that would not be considered engineering. Gender and years of experience were also considered. Recruitment began with identifying a broad range of disciplines by considering the division of academic fields within universities. Next, disciplines were examined based on Goel and Pirolli's (1992) framework to justify the inclusion of that discipline as an area in which it would be likely to find professional designers. Participant discipline choices were also supported by literature descriptions of who could be considered a designer (Cross, 1995; Nelson \& Stolterman, 2003; Zimring \& Craig, 2001).

The final selection of academic fields represented in this study was based on diversity in artifact type (e.g., the design of a product, plan, process, etc.), access to designers, and engineering representation. In total, participants included 13 males and 7 females. Five participants had 5-10 years of experience, four had 10-15 years, three had 15-20 years, and eight had over 20 years of experience. Participants were from the Midwest region, with the exception of one participant from the Southwestern region and one participant from Europe. 
TABLE 1

Study Participants

\begin{tabular}{|c|c|c|c|c|}
\hline Disciplinary Family & Pseudonym & $\begin{array}{l}\text { Self-Identified } \\
\text { Discipline }\end{array}$ & $\begin{array}{c}\text { Years of } \\
\text { Experience }\end{array}$ & Gender \\
\hline Architecture & Alan & Architecture & $15-20$ & Male \\
\hline Consumer and & Omar & Culinary Arts & $10-15$ & Male \\
\hline Family Sciences & Hannah & Fashion Design & $20+$ & Female \\
\hline \multirow[t]{8}{*}{ Engineering } & Charlotte & Chemical Engineering & $5-10$ & Female \\
\hline & Leann & Mechanical Engineering & $5-10$ & Female \\
\hline & Isaac & Mechanical Engineering & $5-10$ & Male \\
\hline & Evelyn & Civil Engineering & $10-15$ & Female \\
\hline & Roberta & Process Engineering & $15-20$ & Female \\
\hline & Svenson & Chemical Engineering & $15-20$ & Male \\
\hline & Bill & Biomedical Engineering & $20+$ & Male \\
\hline & Parker & Civil Engineering & $20+$ & Male \\
\hline Education & Netty & Instructional Design & $10-15$ & Female \\
\hline \multirow[t]{2}{*}{$\begin{array}{l}\text { Sciences and } \\
\text { Education }\end{array}$} & Quentin & $\begin{array}{l}\text { Chemistry and } \\
\text { Educational Research }\end{array}$ & $5-10$ & Male \\
\hline & Marcus & $\begin{array}{l}\text { Experience Design and } \\
\text { Computer Science }\end{array}$ & $20+$ & Male \\
\hline \multirow[t]{4}{*}{ Sciences } & Fritz & Computer Science & $5-10$ & Male \\
\hline & Duncan & Chemistry & $20+$ & Male \\
\hline & Ken & Physics & $20+$ & Male \\
\hline & Tyson & Analytical Chemistry & $20+$ & Male \\
\hline \multirow[t]{2}{*}{ Liberal Arts } & Glenda & Dance Composition & $20+$ & Female \\
\hline & Jack & Painting and Writing & $10-15$ & Male \\
\hline
\end{tabular}

Table 1 summarizes participant information, including disciplinary home, disciplinary family, and pseudonym. The disciplines identified in this table are based on the participants' statements of their home disciplines. The participants should not be assumed to be representative of the breadth of design in their disciplines, but that participants' areas of work should be considered representative of one way of experiencing design that may be unique or shared across disciplines. Disciplinary family was titled according to participants' college home in a university setting.

\section{Data Collection}

A phenomenographic interview is situated in discussions of concrete experiences in order to facilitate participants in sharing their understandings about a specific aspect of the world (Åkerlind, 2005; Bowden \& Marton, 1998; Marton \& Booth, 1997). Discussing 


\begin{tabular}{|c|}
\hline Opening Statements \\
\hline \hline Background \\
\hline \hline Describing Experiences
\end{tabular}

FIGURE 2. Interview protocol overview.

concrete experiences provides a context for participants to reflect on the aspect of the world under investigation (design), and provides a way to elicit meaning and intentional attitude (Åkerlind, 2005; Åkerlind, Bowden, \& Green, 2005). The interview protocol for this study was guided by the goal of prompting participants to discuss their experiences, meanings, and awareness related to design. Figure 2 provides an overview of the interview with example questions. The interview began with structured questions about the individual's background, moved into questions about concrete experiences, and ended with open-ended questions about meanings they associated with design. Interjected in the structured questions were follow-up questions clarifying word choices, asking for reasons, meanings, importance, and values. The answers to these questions provided deep reflective data contextualized within the concrete experience. The length of the interview ranged from 45 minutes to an hour-and-a-half, with the majority of them lasting around an hour.

\section{DataAnalysis}

Phenomenographic categories have logical relationships, which often exist in the form of a hierarchy (Bowden, 2000; Marton \& Booth, 1997). Phenomenographic analysis therefore involves a number of iterations and comparisons among transcripts, which requires continuous sorting and resorting of data initiated by attempts to describe categories and their relationships (Åkerlind, 2005). 


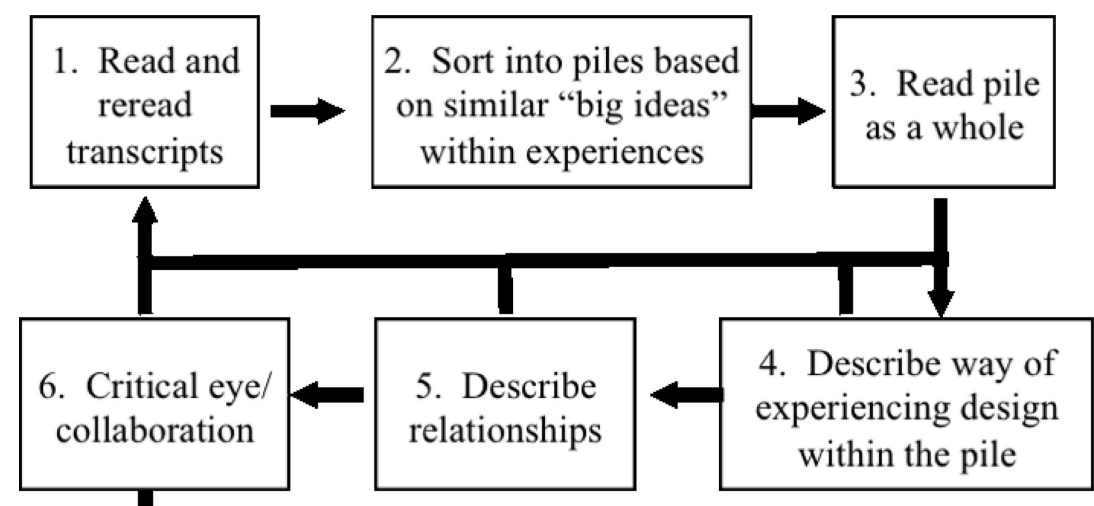

Categories of Description and Relationships

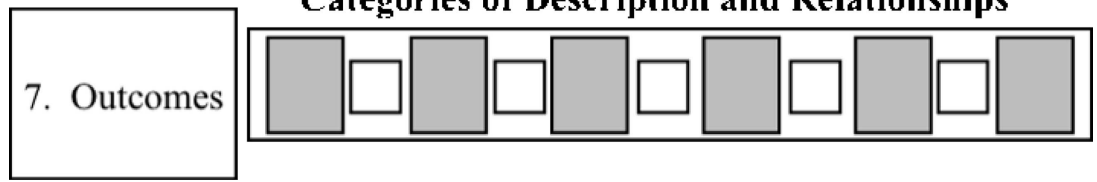

FIGURE 3. Data analysis representation.

The process of phenomenographic analysis involves (1) constructing a limited number of qualitatively different ways an aspect of the world has been experienced and given meaning, (2) describing the critical aspects of what these ways mean, (3) characterizing the relationships between ways, (4) developing the themes of expanding awareness, and (5) identifying if and how the themes of expanding awareness provide evidence of a hierarchy. Figure 3 provides a summary of the data analysis process employed and is not intended to imply a linear or clean stage-by-stage process, but to summarize aspects of an iterative analysis approach; the aspects of the approach are numbered for ease of matching sections of the following paragraphs to an aspect of the approach. The gray rectangles represent piles of transcripts, which became the categories of description and the small white squares represent relationships between categories. Each transcript includes all of the design experiences that the designer discussed within the interview; multiple design experiences were not divided into multiple segments for analysis. An individual interview transcript was viewed as an intact whole, not separated into pieces (Åkerlind et al., 2005).

Categories were generated from empirical evidence rather than based on existing literature or theory, thus data analysis began from scratch, not guided by pre-established categories. The first stage of the process involved reading and re-reading the transcribed interviews as a group for familiarity (1) and so they could be viewed collectively as a whole. Big ideas were summarized and transcripts were sorted into piles based on similarities (2). The transcripts in each pile were read again as a collection (3), resulting in some resorting of piles and additional re-readings. Once the piles represented distinct ideas, a description was generated of how the experiences represented in the transcripts were a way of experiencing design (4). After a description was generated, transcripts in that pile were read again (3), as well as discussed with another researcher with experience in phenomenographic methods (6). Rereading (3) and discussing interview transcripts with other researchers (6) prompted additional iterations on the piles and 
descriptions of the way design was experienced in that group of transcripts. Describing the relationships between the categories also prompted iterations (5). Seven distinct iterations occurred in this study. Critical distinctions of ways an aspect of the world is experienced is not usually obvious; they must be drawn out with rigorous analysis. Thus, iterations occurred as a result of questioning the emphases on which piles were formed and recognizing critical variations between transcripts. In the early stages, there was frequent sorting and resorting in an attempt to determine cohesive groups; later, as iterations ceased and descriptions fully captured the groupings, the descriptions of the relationships between the categories of description were finalized (7).

The following section presents the outcomes of the analysis process as well as the evidence that guided the development of the outcome space.

\section{FINDINGS}

We present summaries of the categories of description as well as evidence supporting them in the form of illustrative quotations. As the transcripts cannot be presented in their entirety, it is important to recognize that these are sample excerpts and that the categories of description were developed based on the transcripts as wholes. We also describe the relationships between the categories with additional excerpts to provide examples of the types of evidence that were used to develop the outcome space.

\section{Categories of Description}

The data revealed six distinct ways designers experienced their design work and these are summarized in Table 2. These categories of description elucidate characteristics of designers' approaches and emphases they applied in their experiences.

In the following six sections, we present each category of description with a summary description of the central distinct aspect reflected in the transcripts as a whole. Three to five illustrative quotations from the transcripts are also included to represent key aspects of the description.

Category 1: Design as evidence-based decision-making. This approach emphasizes the importance of knowing and investigating multiple solution options, using evidence such as data and resources (including other people, documents, and the designer's previous experiences) to make those decisions, and is driven toward finding the best solution for the specific design problem and its component parts. Maintaining records of design decisions for current and future designers and stakeholders is also essential.

If there's some end result that you want and there's no clear pathway, then analytically you should sit down and think about the possible ways to accomplish that and write them all down, or put them in your mind. And then go through a series of evaluations and pick a preferred one and then go back, not throw the others away, but think about them even more and recheck your design and make sure there isn't something you haven't thought of or left out. (Duncan, Chemistry)

We regrouped and said, "Where do we go from here? Where does the design go from here?" Then we ruled out some of these things and there was one group that said, "I don't like this one, I'm going to do some research down this area," and we said, "Fine, go do that. We're going to do this, and may the best experiments win." And so we actually did that. The one that my group came up with was the one that 
TABLE 2

Categories of Description

\begin{tabular}{|c|c|c|}
\hline Category of Description & Summary & $\begin{array}{l}\text { Designers Whose Experiences } \\
\text { Comprise this Category }\end{array}$ \\
\hline $\begin{array}{l}\text { Category 1: } \\
\text { Evidence-Based } \\
\text { Decision-Making }\end{array}$ & $\begin{array}{l}\text { Design is finding and creating } \\
\text { alternatives, then choosing among } \\
\text { them through evidence-based } \\
\text { decisions that lead to determining the } \\
\text { best solution for a specific problem. }\end{array}$ & $\begin{array}{l}\text { Duncan (Chemistry) } \\
\text { Evelyn (Civil Engineering) }\end{array}$ \\
\hline $\begin{array}{l}\text { Category 2: Organized } \\
\text { Translation }\end{array}$ & $\begin{array}{l}\text { Design is organized translation from } \\
\text { an idea to a plan, product, or process } \\
\text { that works in a given situation. }\end{array}$ & $\begin{array}{l}\text { Charlotte (Chemical } \\
\text { Engineering) } \\
\text { Glenda (Dance Composition) } \\
\text { Leann (Mechanical } \\
\text { Engineering) } \\
\text { Parker (Civil Engineering) }\end{array}$ \\
\hline $\begin{array}{l}\text { Category 3: Personal } \\
\text { Synthesis }\end{array}$ & $\begin{array}{l}\text { Design is personal synthesis of } \\
\text { aspects of previous experiences, } \\
\text { similar tasks, technical knowledge, } \\
\text { and/or others' contributions to } \\
\text { achieve a goal. }\end{array}$ & $\begin{array}{l}\text { Hannah (Fashion Design) } \\
\text { Netty (Instructional Design) } \\
\text { Omar (Culinary Arts) } \\
\text { Quentin (Chemistry and } \\
\text { Educational Research) } \\
\text { Roberta (Chemical } \\
\text { Engineering) }\end{array}$ \\
\hline $\begin{array}{l}\text { Category 4: Intentional } \\
\text { Progression }\end{array}$ & $\begin{array}{l}\text { Design is dynamic intentional } \\
\text { progression toward something that } \\
\text { can be developed and built upon in } \\
\text { the future within a context larger } \\
\text { than the immediate task. }\end{array}$ & $\begin{array}{l}\text { Alan (Architecture) } \\
\text { Fritz (Computer Science) } \\
\text { Isaac (Mechanical } \\
\text { Engineering) } \\
\text { Ken (Physics) }\end{array}$ \\
\hline $\begin{array}{l}\text { Category 5: Directed } \\
\text { Creative Exploration }\end{array}$ & $\begin{array}{l}\text { Design is directed creative } \\
\text { exploration to develop an outcome } \\
\text { with value for others, guided and } \\
\text { adapted by discoveries made during } \\
\text { exploration. }\end{array}$ & $\begin{array}{l}\text { Bill (Biomedical Engineering) } \\
\text { Svenson (Chemical } \\
\text { Engineering) } \\
\text { Tyson (Analytical Chemistry) }\end{array}$ \\
\hline Category 6: Freedom & $\begin{array}{l}\text { Design is freedom to create any of an } \\
\text { endless number of possible outcomes } \\
\text { that have never existed with meaning } \\
\text { for others and/or oneself within } \\
\text { flexible and fluid boundaries. }\end{array}$ & $\begin{array}{l}\text { Jack (Painting and Writing) } \\
\text { Marcus (Experience Design } \\
\text { and Computer Science) }\end{array}$ \\
\hline
\end{tabular}

eventually won. But I knew it would because it was scientifically based every step of the way and I had faith in the scientific method. (Duncan, Chemistry)

The best thing that we did was document our decisions and where this is specific for us is because the scope of this project expanded so much... We had designed to make sure that it was nicely uniform and when it was constructed it was way out of whack and they were getting complaints from the homeowners on the water that it just wasn't attractive. He had to go back and say, because the contractor's always going to say, when it was designed it wasn't out of whack. So if you can't go back 
and say, "No, it's right here ..." So documentation is huge, especially if you have any kind of complex element. To me, even the simple stuff should be documented, but anything complex that requires someone outside of your office or someone [with] expertise, because in my opinion, if it took you that long to figure it out or if you had to look it up - write it down. That's probably the best thing that we did. (Evelyn, Civil Engineering)

What it's about is solutions and it's about finding the best solution for whatever the problem is. And it may seem a little mundane that you have the same set of beams that you use, but in the end, it's a solution. (Evelyn, Civil Engineering)

Design as organized translation. A second lens on what it means to experience design focuses on translating an idea into a product that works in the context of the design task. The word translation captures the way designers using this approach combine and interpret information and ideas, and structure strategies for moving toward a solution. This translation happens in an organized and systematic manner, although not necessarily linear or step-bystep, as it involves fluidity and iteration-based evaluation of ideas and balancing many aspects of the design space at once. Organized translation as an approach does not imply a direct path, but instead a big picture lens of the problem and a focus on mapping out the way to a solution. The solution goal is not necessarily a best solution, but a solution that works according to the situation, including the people involved in the solutions, technical and logistical aspects of the outcome, and the ability of the solution to meet the needs of the problem.

My task list with the first project around the quality systems ... just kept changing so it was very hard to keep up and keep reprioritizing so I had to just kind of do the best I could... I drafted up a plan of what I thought I would need to test in order to figure out whether this was going to work. (Charlotte, Chemical Engineering)

I consider design finding a solution for which an answer is not available. You go through a trial and error so you try to test, does the model work? That's what you have to do, you have to test continuously whether your design will work. (Parker, Civil Engineering).

It's more about constructing a piece, putting movements together to make a phrase, to make a whole dance... for me design is the whole picture cut up into little pieces, movements to phrases to the whole dance... (Glenda, Dance Composition)

I might think that I have a great idea, a great way to do something, but if I'm not the person doing it every day, surely there are things I don't understand. Sometimes it takes somebody pointing out the obvious and saying, "Duh, you forgot that we have to do X, Y, Z." "Oh yeah." So getting input earlier in the process and not try to shoulder the whole burden of design. I think designing means to be a team, it needs to be "we." "We" needs to be the people that are going to be using it, implementing it and working with it. Those are the folks that suffer when it doesn't work... If somebody said, "Gosh, the way you're asking me to do this really I have to walk to and from my office six more times than I think I need to and it's just a complete waste of time, can we do it this other way." If there was nothing that violated any procedures or policies that were fixed, then sure, let's change it; let's make it easier for the people who are using it. (Charlotte, Chemical Engineering) 
Design as personal synthesis. This design approach emphasizes a synthesis of multifaceted resources through the human lens of the designer. The resources available are numerous, and include previous similar designs, others' work and ideas, and personal experiences and knowledge. The designer (or team of designers) synthesizes design ideas by drawing on their personal lens to create something new. This approach relies on a sophisticated personal lens, thus a key aspect is also to build experiences that create intuition and a repertoire. Both achieving a goal and adding to the designer's personal repertoire drive this design approach.

There were designs for hydrogen recovery and there were designs for ... liquid recovery, but not together, so you would take those two things and mesh them together and use that as your starting point. The company that I was at, there was very little starting with a blank sheet of paper type design. That's how you'd get started. You'd go back and take some aspects of this and this and put them together... You use these experts, you use your knowledge based on your experience, and then sometimes you let the simulator come up with the new ideas. So there's kind of three areas that you tap into when you're doing that brainstorming phase around what's my cycle, what's my process going to look like. (Roberta, Chemical Engineering)

If it's your spin on things then how could anyone else teach you what you ought to do, because you decide on your own. You're obviously influenced by the literature and by other people, but ultimately it's up to you ... ultimately it's always you getting it done and so you're the one designing things, you're the one deciding exactly how you want to perform a reaction even if it's a literature-precedent, you decide if you want to change anything, if you have to change anything because the molecule is slightly different. Again it's all you in the driver's seat. (Quentin, Chemistry and Educational Research)

I probably saw it somewhere and had it tucked somewhere in the back of my head and pulled it out like a file card. And I thought, oh that would work for this one, and it's got this other third element to it, so it will be interesting... Do whatever you can to build your repertoire and then if you have it, how it all comes together in your head, is the mystery part. I don't know if there's any way to consciously guide that or direct that, but what you can do is consciously build your repertoire and then let it happen on its own... It's that foundation of technique and repertoire on top of that and how those work together is what makes for a really good design... (Omar, Culinary Arts)

That's like my overall idea of how the concepts that we're working on, maybe one unit, fits in with the next unit and the unit after that, how everything is going to tie together at the end so the students get a better understanding of chemistry in general. Where do I want them to be, and what are they going to be doing and thinking about throughout the unit that's going to play a role in this? That it's not just them doing stuff but also thinking about it and putting the ideas together. What do I need to help them create, to help them put all these concepts together for themselves? (Netty, Instructional Design)

Design as intentional progression. This design strategy is focused on the potential a design has for progress, which specifically takes a larger context of the design into account. 
The larger context is both the situational context outside of the design itself and the context of time because the design could be a building block for future work and progress. Designers with this strategy are guided by their awareness of the continual nature of design, that their designs build on previous work, and that these new designs can facilitate future work. They aim for their designs to be a contribution to a larger goal, for example, to further develop theory or build solutions that can serve as foundations for later improvements as capabilities grow.

So I have some idea about the way say, metals conduct and it's based on some reasonable expectations, someone's theory or calculation and I design an experiment to test the specifics of that. And that's a lot different than just making some hypothesis out of the blue and seeing if it's true or not. That doesn't necessarily get you closer to constructing this theoretical framework. So when I think about designing an experiment, I first ask what big principle of physics am I testing. What important area or theory am I aiming to test and how am I going to do a test that's really going to give you something conclusive about the test. So ideally, I have the test in mind, I understand all the pluses and minuses and the ins and outs of that test, and then ideally I design an experiment that no matter what answer I get, it's given me some useful information about this theory. (Ken, Physics)

Most of our work was so custom that you really didn't get the chance to improve on your previous work.... A lot of it is replicating it off of the previous mixer and then just trying to fix problems you had with the last iteration of the mixer... Again, you never get everything perfect - there is no ideal. But each time, there were definitely improvements... Unfortunately I only have a picture of the last one so you can't necessarily see the progression... I was trying to come up with a design that could fit many different applications. So that's what was really different. I didn't have a specific customer in mind. I was trying to come up with a design that would fit most of the applications that we would come in contact with in the future. (Isaac, Mechanical Engineering)

With software development we're trained to do things correctly to always build things so they're expandable, so you can manage the code easily. So anybody can come in and add $\mathrm{x}, \mathrm{y}$ feature really easily... That's the worst thing as far as design goes for software development is having to go in and say we're starting over. All that code, all that data, all that work that companies have paid for is just literally going out the window. So I guess in the formal training aspect, we're taught to manage our code in that sense - to make things expandable, to make things stable to be built upon easily. (Fritz, Computer Science)

I'm always asking myself, am I doing things right and what can I do to change the way I'm doing things so that it will be more relevant to what I am now, to what the world is now... You can't build mundane things; you can't build dull things. It has to be something that people love in some sense. (Alan, Architecture)

Design as directed creative exploration. The focus of this category is on exploration, but this exploration is on a strategic and directed path toward an outcome that will have value. The outcome of design tasks guided by this approach are viewed as extremely flexible or unspecific at the starting point and molded throughout the task, as the designers are open to where design explorations lead them. Designers described a process of allowing fluidity and 
having courage to explore emergent ideas and pathways. This strategically directed path provides designers with opportunities that could not have been predicted, however, that also leaves them open to potential failure. These risks require designers using this approach to have courage and technical knowledge as they venture outside of "playing it safe."

We'd go in the lab and play with stuff and see what comes out of it and that to me is an early phase of any design. You have a general idea of what you want and you have a general idea of what you're working with, and you start doing things, causing those things that you are working with to interact and seeing what happens. It's somewhat of an improvisational schema to see what you can create and new things that happen... So it's a process of discovery, observation, sometimes iterations of - I did it this way and that happened, what if I do it this way, what happens. (Bill, Biomedical Engineering)

I think that to be a top-notch scientist you have to see relationships that other people don't see and so throughout my whole career, I've looked at things that other people have done and said, oh, I can use that. So I can map that into stuff I want to do although nobody has ever said that it ought to work for what you want to do. (Tyson, Analytical Chemistry)

Sometimes that means you just try something. Ready, fire, aim. Because that's what happens. A lot of things come out of a ready, fire, aim mentality. You try something and it didn't hit my target, but I was close enough or I hit some other target. Now I'm going to take it over here and use it. (Svenson, Chemical Engineering)

Design as freedom. This approach is guided by the conception that design is freedom to create any number of outcomes that have never been generated before and that have meaning for others or for the designers themselves. Designers with this approach welcome ambiguity and define and redefine their own boundaries and constraints. They perceive constraints as directing their free exploration of design problems and solutions as opposed to limiting solution possibilities. The boundaries of design tasks were discussed as a function of the meaning the designers associated with the outcomes, where designers felt free to choose a design path as long as there was real value to the possible outcomes.

Design, for me, blossoms from constraints, so it's knowing how the world is constrained gives you freedom. I give the analogy in pure science terms of the move from assembly language to higher-level program languages. When people first started proposing Fortran, programmers freaked out and said, "We can't do all the things that we do. We don't have the same power that we had." And yet if we had never done that we would have not been able to build the things that we've built, because we were dealing at a level of abstraction that was too low to build. So by moving to a higher level of language we imposed constraints but those constraints gave us power. (Marcus, Experience Design and Computer Science)

We'll say right off the bat that the final product was not something anybody expected and it was a surprise to me and to you as well. (Jack, Painting and Writing)

So I think a word like design, meaning, get up in the morning and set out boundaries for yourself and pick where to go with this - you have a task to 
accomplish which is finish this set of acrylic polymers slapped on canvas in whatever way - there's definitely a road toward finishing that product that you could call design... I think, yes, what started as a nice big way to do an exercise, to work on skills, turned into something I recognized as something that I didn't feel like painting over. So instead of just practice - not just because I think practice is very important-but I think that thing could have easily turned into what was underneath it, which is a step on the way to doing something else without it ever being represented again unless somebody $\mathrm{x}$-rays the thing someday. (Jack, Painting and Writing)

This notion that you're physically immersed in an imaginary phenomenon that is persistent over a long period of time and that you're embedded in these phenomena and the phenomena and embedded in this physical space and these activities run for weeks - that's an unusual form factor and one which has worked for me in both the human computer interaction community where that's kind of unusual and definitely in the educational community, that's very unusual. So I think it's been successful in defining a new genre of activity... I think the greater success is to find design frameworks. Instances can always be - there's always room for improvement in the design, but a central conception - specifying the constraints of a space of design, I think that's more interesting. (Marcus, Experience Design and Computer Science)

\section{Relationships Among Approaches}

The results of the analysis of the relationships among the categories yielded a hierarchical and increasingly comprehensive view and approach to design. The phrase "more comprehensive" is used interchangeably with "greater awareness;" this is terminology used in phenomenography to describe the inclusive relationships among categories of description. In the findings from this study, with the exception of the foundational category (Design as Evidence-Based Decision Making), each distinct approach to design incorporates aspects of the less comprehensive categories, but emphasizes something extra. What makes each lens on design distinct is the central focus that designers related within the context of their design experiences. The data collected could not be used to investigate potential learning progressions, thus the results do not indicate what the path is to embody a more comprehensive lens, but they do indicate that the designers who had a more comprehensive lens also discussed aspects of the categories of description that were less comprehensive.

A pictorial representation of the outcome space is presented in Figure 4. Relationships between the categories of description are represented by a short phase that characterizes the primary attribute of the category that makes it distinct. As the relationship among categories was found to be hierarchical, the figure illustrates this hierarchy in terms of expanding hemispheres of awareness from less comprehensive (center) to more comprehensive (outer circle) understandings of what it means to design. This does not imply worse or better understandings.

General trends in the hierarchy include a wider consideration of context from the immediate problem to a wider population and environment beyond the problem itself, a movement from a solution-focused design approach to one that is problem-focused, and a change of who defines the problem as well as evaluates the design, moving from others to the designer himself. The meaning of phrases above the arrows are unpacked in the following paragraphs, with an excerpt from a participant that provides a sample of the type of information that contributed to the development of the hierarchy. 


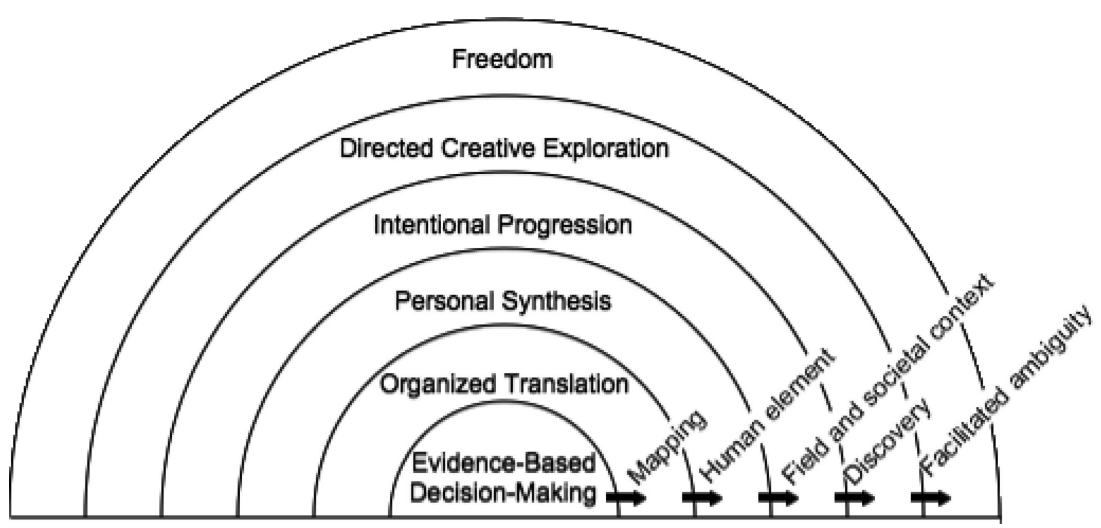

FIGURE 4. Outcome space in hierarchical form.

An approach to design as organized translation is distinct to design as evidence based-decision making because the designer emphasizes the consideration of the entire design space as a collection of aspects that needs to be considered together in addition to the recognition of discrete decision points and experiences within a design task. The word mapping represents an expansion of awareness from decisions grounded in evidence for each piece of the design task to an emphasis on understanding how each piece fits in the scope of the problem space and will impact other components. While designers using either approach rely on evidence to make decisions, designers who approach design as translation view their goal as working toward a solution that satisfies the stakeholders and constraints, not a best solution. Approaching design as organized translation includes the notion of using foundational knowledge and evidence to make decisions and also builds on approaching design as evidencebased decision-making by emphasizing the broader path from the start to the end state. This path is organized and directed, and the designer continues to question whether or not the current design idea is going to achieve the target goal.

One example of the type of evidence that contributed to the development of the hierarchy can be seen in Charlotte's discussion of the translation of ideas to outcomes in addition to comments about evidence in the form of resources when making decisions, as well as the importance of documentation. Whereas the transcript as a whole contributed to hierarchy development, this excerpt highlights the way Charlotte (Chemical Engineering) discussed aspects of category 1 , but also emphasized the connections between parts, what she calls, "information flow management."

I started by pulling all the documents and figuring out what does the outside of the box look like, what does the system have to meet. And then started thinking about how the individual pieces were gonna work, like the inputs and the outputs and what information is - partially it becomes an information flow management. What information is going to come from where and who needs to be told what and assigning responsibilities, who is going to have responsibility for what aspect.... And I guess looking at other reports from people that had maybe done similar kinds of things to make sure that I wasn't missing some critical aspect that by 
changing this butt length I wasn't going to cause something really bad to happen in the end product.

This excerpt included a discussion on aspects of category 1 such as evidence and documentation, but included emphasis on other aspects such as a fluid and organized translation. In this way, category 2 represents a more comprehensive view of design than category 1. The experiences in category 2 , as well as category 1 , do not include questioning the nature of the design problem itself. Finding the solution is the goal; the experiences are solution-directed.

A critical variation between approaching design as translation and approaching design as personal synthesis is the emphasis on the human element of design. The designer makes choices and formulates ideas based on previous experiences and personal preferences, thus it is important for the designer to be knowledgeable and informed. Data from the study participants revealed that those who approached design in this way also utilized data to inform their design decisions, generated alternatives, and valued iteration as they considered multiple aspects impacting the design outcomes. However, their awareness centered on recognizing themselves as a conduit, collecting pieces from themselves and other sources to mold an outcome. An example of this emphasis is highlighted in an excerpt from Quentin (Chemistry and Educational Researcher). Just as the designers whose experiences comprised category 2 , he discussed the relatedness of parts of the problem and navigating those parts to achieve an outcome; however, in addition, he highlighted his personal impact on the work. He also discussed the power of resources as a basis for decision-making (as did designers whose experiences comprised category 1 ). The excerpt is an example of his acknowledgement of the power of resources, but also his greater emphasis on personal knowledge and experience in the interpretation and decisions related to those resources.

I still think that it was still - read the literature, figure out where you're sitting, what you're going to look at, how you approach the problem based on what other people had done, and then you have to personally decide what your take on it is going to be... you always go through that same process of consulting what's been done before and then you put your take on it. And you take it all in your mind and you synthesize it and put your own personal spin on where you're going to go with it.

Statements like these informed the hierarchy of categories of description. While both categories 1 and 2 involved looking to others' work when making decisions, those whose experiences comprised category 3 discussed the many different pieces of others' work as well as their own experiences that they synthesized through their own personal lens.

An approach to design as personal synthesis is differentiated from design as intentional progression because designers with the latter approach focus on the larger context of their experiences, specifically the relationship of their work to the context of their field and to society. Those with a design approach of intentional progression consider context as larger than the immediate project, thus the goals of the designs are aimed at something that creates a better situation in the present and the long run, and can be further built upon. There is an awareness of the dimension of time and the evolution possibilities of the design in the future. The larger context also includes learning experiences of the designer; designers build their repertoire through the design experiences, progressing their own abilities. Excerpts from Isaac's (Mechanical Engineering) discussion of experiencing design are included below. The first highlights resources used in his work (similar to the emphasis of category 1 ) as well as how he mapped aspects of the problem to see how they all connected (similar to 
the emphasis of category 2). The second excerpt includes evidence of the incorporation of his personal lens to his design work (similar to the emphasis of category 3 ), and the third excerpt highlights his consideration of context.

I used the same approach - not to be so narrow, but to look at all the other people that could be resources. And that's really where design comes in, how to fit all the pieces together.

I think, personally, I have a talent when it comes to designing with steel and I think there's a lot of creativity that I put in to that made the improvements kind of special and I think clever, even.

It actually made it more of a complicated design but it saved me time in the future because then I didn't have to spend so much time doing custom design. So from an engineering point of view, it saved money in the long run with a slight premium on the fabrication, but it over time it would have paid for itself.

A more comprehensive view of design than an approach to design as intentional progression is an approach to design as directed creative exploration, as design is recognized as a task with bounds, but a great deal of flexibility and room for exploration can be experienced within those bounds. Discovery, and openness to discovery, informed the design path and the outcome. The move from category 4 to 5 emphasized a constant eye to seeing what new things could emerge, and going on paths that were not anticipated at the beginning of the work. As one example, Bill's transcript excerpts below include evidence of this lens on design as well as the other aspects emphasized by designers whose experiences were in less comprehensive categories. As Bill (Biomedical Engineering) did not discuss all of these pieces in a single paragraph, shorter clips are included to demonstrate evidence of each piece. In parentheses before his excerpts are the categories of description of which the quotation shows a sample of the evidence that guided the hierarchical choices.

(Evidence-Based Decision Making): To prepare... we designed it on paper, then we gathered the components. We actually tested it with a group of students... At each phase we were asking questions. Is this working, is this close, does it meet the criteria, what's wrong, how can we do that better.

(Organized Translation): So there was criteria at several levels, there were inputs from several levels and an end point and we had to fit the pieces together.

(Personal Synthesis): What happens is usually you make a change and it takes you closer or it takes you further away and then you back up and do it again. And there's an intuitive process in that as well. In the play, I think a good designer is always using a background of knowledge and intuition about how things have worked.

(Intentional Progression): Ultimately you could say, you're not ever really finished in that exploration process because new things can be created from what you've already created.

(Directed Creative Exploration): An important part of that is to be observant, being creative about thinking, not limiting yourself to what could happen by what you already know... As you observe outcomes that look interesting or look like they are nearer to what you're trying to achieve or where you're trying to get, obviously the 
"play" that becomes design has usually a goal or a need that is going to be fulfilled, whether it's a device or a process.

Category 5 emphasized the ability to explore and experiment with ideas in the context of an organized approach. It also emphasized that these explorations may lead to a change in course, but the end product is still an outcome with value. Design decisions are based on evidence, ideas involve synthesis, and experimentation and exploration facilitate progress.

A critical variation between an approach to design as directed creative exploration and an approach to design as freedom is the welcomed and facilitated ambiguity of the start and end state and the path from the start to the end state of a design. Facilitated ambiguity means that the designers worked to maintain the open-endedness of the problem as they worked through the task. This would allow new ideas and possibilities to emerge and put in place a mechanism to prevent self-imposed constraints from increasing limitations. An approach to design as freedom emphasizes an appreciation and facilitation of ambiguity in the design task throughout the design experience. Freedom comes from the limitless possibilities that exist within the constraints of a design task. As in the previous example, excerpts from a designer's discussion, in this case, Marcus, elucidate samples of the types of comments that guided the development of the hierarchy. The excerpts from Marcus (Experience Design and Computer Science) in the previous section provide additional examples of his design approach.

(Evidence-Based Decision Making): So I started going to meetings of this larger center and started chatting with domain experts trying to get some ideas about what I might do that would connect. I started interviewing [her] and trying to understand her craft.

(Organized Translation): I was taught ways of taking complex problems and breaking them down into components and I was taught notation systems that I could use to brainstorm things and that would somehow lead to design.

(Personal Synthesis): It's one thing to feel an earthquake, but I guess I feel a need to quantify things. Maybe that's my cutting edge. It's not even that. I'm a believer in observation. You can count things and describe things, but just to feel with no work associated with an activity, that seemed to me to be lame.

(Intentional Progression): I think it was a success in defining a new kind of form factor for classroom activity. This notion that you're physically immersed in an imaginary phenomenon that is persistent over a long period of time and that you're embedded in these phenomena and the phenomena are embedded in this physical space and these activities run for weeks.

(Directed, Creative Exploration): I think both of them had some creativity associated with them... When I started the earthquake stuff I hadn't thought about this phenomena framework before so I definitely was not coming at it with preconceived constraints.

(Freedom): The incremental advance is clear and it's direct and there's steps along the way and it seemed to me to be infinitely boring. So I would rather fail spectacularly than do that kind of stuff. I think it's knowing your constraints and living within your constraints and designing a cool set of constraints, of course... Now it's human experience and there's a lot more freedom which makes design harder. 
This category placed emphasis on the freedom that design opportunities allowed these designers. The experience of designing still involved the aspects emphasized in the other categories; however, these designers were passionate about their experiences because of the freedoms design offered them.

\section{Discussion}

The outcomes of this work included six distinct ways of experiencing design, specifically: design as evidence-based decision-making, organized translation, personal synthesis, intentional progression, directed creative exploration, and freedom. These categories, along with the relationships among them, shaped the outcome space. The outcome space does not represent a taxonomy, consisting of mutually independent categories, but instead represents a hierarchy, consisting of mutually dependent categories.

The outcome of this design phenomenography fills a gap in the results of studies that investigate what designers do in action, i.e., the skills and knowledge they bring to a design task, by answering questions about how designers view, approach, and proceed through design work as well as the result of designers' synthesis of their knowledge, skills, and experiences. The outcomes of the work also provide a framework for design learning, and an example of this framework in practice is discussed further in this section.

The discussion section focuses on the distinctions among categories, thus themes that emerged across multiple categories or the group of categories as a whole are not emphasized. For example, many of the designers' experiences that comprised the categories discussed an awareness of users and stakeholders. As shown in our literature review, we anticipated that participants might discuss these social and human aspects of design. It is important to note that the categories emerged bottom-up from an analysis of full transcripts. Thus, while these aspects were evident and can be seen in the results section, they did not emerge as qualitatively different ways of experiencing design. This is not to suggest that these ideas are not important, but that a focus on identifying qualitatively different ways of experiencing design did not reveal qualitatively different ways of experiencing the human or social aspects of design.

Reasons that social and human aspects did not emerge as distinct could include: (1) the social aspects are more of a theme across all experiences, as opposed to a distinction among groups; (2) the participants were selected based on varied design experiences across disciplines as opposed to varied experiences with social and human contexts (if a goal was to understand the human-centered aspects this would have been realized through participant selection and a modified interview protocol and would be a different study, e.g., Zoltowski et al., 2012); and (3) social contextual factors of design were more evident in higher categories (e.g., Category 4 and beyond) suggesting that an awareness of the social contextual aspects of design may not be a theme of expanding awareness across all categories, but rather indicative of a more comprehensive understanding of design. Research on the social and contextual aspects of design would support this conclusion (e.g., Bucciarelli, 1996; Cross, 2001; Kilgore, Atman, Yasuhara, Barker, \& Morozov, 2007). The above reasons that social factors did not emerge as a distinction among categories can be analogized to other important aspects of design that did not emerge as distinctions in this study.

The following discussion is applicable to designers of many disciplines; however, the knowledge of ways all designers approach their work informs our knowledge of engineering design and how to support novice engineering designers in their transition to becoming professionals. As the categories do not represent better or worse ways of viewing design, each of 
the lenses revealed in this study can inform novice designers as they come to form their own approaches to design and develop expertise.

In the following two sections we highlight theoretical and practical implications of this work. Theoretical implications emphasize how study findings contribute to the literature base on design knowing and learning, which is a foundation for our understanding of how engineers design. Study findings reveal lenses designers have on their design work, and articulate critical variations that have implications for design teaching and learning. Practical implications emphasize using research findings to structure variation-based reflective practice to help engineering students develop an awareness of their own understandings of design and variations in understandings as described by peers, collaborators, and experts.

\section{Theoretical Implications}

Much of the current research literature specifies skills and knowledge associated with design (Dym et al., 2005) and extracted or prescribed process models (Dubberly, 2004); however, less work exists related to how skills and knowledge fit together with each other and with process models to form a designer's approach to design work. Expert designers do not follow a process step by step; they make their own paths, guided by their own learned conceptions and priorities. The outcome of their work is dependent on the paths they choose and differ according to the priorities they set.

This research has revealed six distinct ways designers have connected their skills and knowledge related to design with their priorities and conceptions, what we call a design lens. Critical aspects of this lens on design can be connected to the knowledge and skills discussed in the design literature and presented in the Research Framework section. These are elucidated below in Table 3. A unique contribution of our work is revealing the emphases designers placed on certain aspects of design (and not others), thereby creating an important bridge between what designers do and why they do what they do. This bridge is the design lens, representing how a designer's understanding is embodied through their actions.

The results of this work reveal outcomes of how designers combine the skills, knowledge, and experiences they have with design and what aspects of design they emphasize. We propose that this design lens is simultaneously shaped by past design work and influences future design work. It was evident in all of the designer interviews that the experiences they described had influenced the ways they viewed design work. Designers enact theses lenses as approaches in practice and their approaches impact the ways they experience their work. New experiences must be integrated into designers' lenses, and these modified lenses will impact designers' approaches to their new work, creating and continuing a cycle (see Figure 5). This cycle illustrates a process of learning as new experiences could lead to revisions to a designer's lens and new approaches to design.

A formulated example cannot elucidate all of the complexities of one's view on design; however, a simplified, concrete example of this cycle is described in the following sentences to provide further explanation of the connection between experience, lens, and approach. Imagine a designer, Debbie, has begun working on the design of a solar cooking device. She has been involved in previous design experiences in which the team focused on gathering resources and making evaluations of those resources to generate combinations of suggested ideas. The experiences Debbie had on the team contributed to the way she views design work, i.e., her lens on design. She emphasizes the collection of ideas from her own knowledge and experience base as well as others', and uses these to guide the progress of the design. Thus, the experiences influence her lens, and her lens influences how she approaches the solar cooking design. She seeks out extensive materials 
TABLE 3

Literature Connections to Design Approaches

\begin{tabular}{|c|c|}
\hline Design Approach & Aspects of this Approach in the Literature \\
\hline $\begin{array}{l}\text { Evidence-Based } \\
\text { Decision Making }\end{array}$ & $\begin{array}{l}\text { - Design as logical decision making and searching (Simon, 1969) } \\
\text { - Judgment with respect to intentions (Nelson \& Stolterman, 2003) } \\
\text { - Decision making in design based on logic, evidence, and strategy when } \\
\text { making decisions (Lewis, Chen, \& Schmidt, 2006) }\end{array}$ \\
\hline $\begin{array}{l}\text { Organized } \\
\text { Translation }\end{array}$ & $\begin{array}{l}\text { - Converting an ill-structured problem into a well-structured one (Newell } \\
\text { \& Simon, 1972; Simon, 1969) } \\
\text { - The design approach as a rational plan (Simon, 1969) } \\
\text { - Guided by situation specific intention (Rowland, 2004) }\end{array}$ \\
\hline Personal Synthesis & $\begin{array}{l}\text { - Synthesis as a key feature of design (Cross, 1982; Simon, 1969) } \\
\text { - Personalized stopping rules (Ritell \& Webber, 1973; Goel \& Pirolli, 1992) }\end{array}$ \\
\hline $\begin{array}{l}\text { Dynamic Intentional } \\
\text { Progression }\end{array}$ & $\begin{array}{l}\text { - Design guided by intention, intentional openness to be creative } \\
\text { and reflective, and is both context and situation-specific (Nelson \& } \\
\text { Stolterman, 2003; Rowland, 2004) }\end{array}$ \\
\hline $\begin{array}{l}\text { Directed Creative } \\
\text { Exploration }\end{array}$ & $\begin{array}{l}\text { - Design as a structured (or directed) process that is principled even } \\
\text { though there may be opportunistic deviations (Cross, 2001) } \\
\text { - Discovery in design and the element of "surprise" back-talk as a result of } \\
\text { reflective practice (Schön, 1993) }\end{array}$ \\
\hline Freedom & $\begin{array}{l}\text { Tolerance for ambiguity and recognizing that problems require } \\
\text { formulation and structuring that the designer chooses his or herself } \\
\text { (Cross, 2004) } \\
\text { - Order is imposed instead of found by the designer, as the designer has } \\
\text { the freedom to redefine the problem via solution conjectures (Akin \& } \\
\text { Lin, 1995) }\end{array}$ \\
\hline
\end{tabular}

on the market, connects those materials to personal experiences and knowledge related to cooking, and evaluates ideas and determines progress according to both experience and resources. During that process, she discovers that the people who will use the artifact have limited economic resources, and considers a design that may be able to be used for an additional purpose besides cooking. This experience is added to her repertoire, and influences her design lens. In her next design project, her approach also includes an emphasis on the context of the artifact, and she works to generate designs that have additional purposes both in the present and the future.

In more general terms, if a designer comes to a design task with a lens of personal synthesis, he or she will likely seek out resources, consider personal experiences and previous knowledge, and attempt to connect those pieces together to inform possible design outcomes. Alternatively, if a designer comes to a task with a lens of design as intentional progression, he or she is likely to spend time considering previous related work that could be built upon with this new task, the impacts the outcomes could have on the context larger 


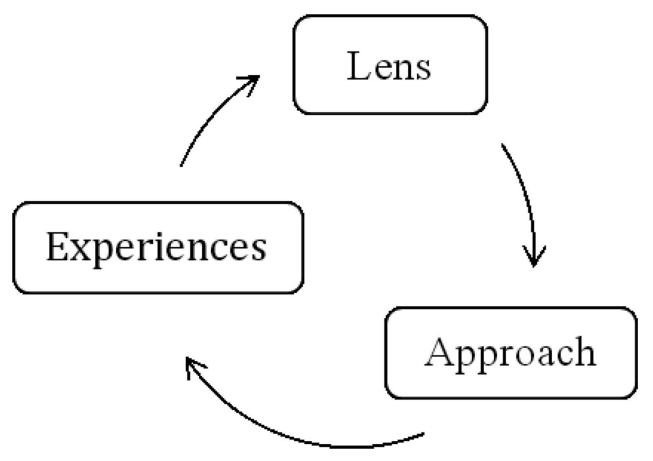

FIGURE 5. impact of impact of design experiences, lens, and approach.

than the immediate project, and the potential various outcomes have for further growth. Neither of these approaches is "right" or "wrong," but they emphasize different aspects, as guided by different understandings of design, and they result in different outcomes. This scenario has additional implications when we anticipate the presence of multiple design lenses when diverse people come together to address grand challenges.

\section{Practical Implications}

One goal of understanding multiple distinct approaches to design is to facilitate engineering students in their development into more informed designers. For engineering students to be successful integrating new approaches, they have to become aware of their own conceptions and practices and how those conceptions and practices vary from others. This approach to learning is grounded in variation theory, which holds that learning about a phenomenon occurs when learners are aware of the variation in ways of experiencing and understanding that phenomenon, including one's own understanding, and engage with those variations (Bowden \&Marton, 1998; Marton \& Booth, 1997; Marton \& Tsui, 2004; Pang, 2003). Thus, learning happens when the contrast between the new and previous experiences and conceptions are integrated.

The implications of this work propose a specific type of reflection-structured reflection grounded in variation theory. Reflection in design education contexts has been discussed and investigated in some design research work and utilized by many design educators; however, research suggests it may not be happening as much as it should (Mehalik \& Schunn, 2006), and the proposed reflection is a unique type of reflection.

Structured reflection exercises help students discern trends in the ways they go about their design work and think metacognitively; in addition to these strengths, variation-based structured reflection exercises help students distinguish differences in design approaches, and recognize how these differences represent critical awarenesses they can develop as they learn to become professional designers. In the following paragraphs we provide three examples of variation-based structured reflection exercises engineering educators can incorporate into classroom environments. The first focuses on students helping each other develop an awareness of their own design lens and the aspects that make them unique from other 
students, the second focuses on students comparing and contrasting their own experiences with those of the study participants, and the third on helping students experience the results of a variation in approach by "reflecting-in-action" (Schön, 1993).

Students can be instructed to write and/ or share with a partner an experience they had designing and the details involved in the experience, such as the goal of the project, how they approached it from beginning to end, why they approached it that way, what was important about their approach, what they learned from the experience, etc. In many ways, this is similar to the interview protocol used in this study. Partners ask questions to facilitate each other in gaining an in-depth understanding of the approach. This reflective sharing of experiences can be done multiple times, if necessary, to gain enough information to characterize some key ideas about how each student understands and approaches design. Once partners have pulled out key aspects of their approaches, each individual student characterizes the ideas and strategies he or she uses to design. Then, as students have a firm understanding of the characteristics that constitute their own approaches, they should engage in comparing their approaches and the key features of their approaches to one another. Example guiding questions include: How do you think the outcome of your design would have been affected if you had engaged in this other approach? What actions would be different if you employed that approach? In what ways might this other approach be more fruitful than your own approach?

Study findings may also serve as resources for students to reflect on their own approaches, discuss similarities and differences among approaches described in the study, and recognize there is no single "right" approach, but critical variations that emphasize different design strategies and goals. For example, students can be instructed to translate the approaches described in this study into actions engineering students could take in the context of their own design work. They could then compare how these actions would be similar or different than strategies they would typically use. This is followed by a guided written reflection or discussion using such questions as: Why do we care what lens and approach a designer has? Why might a designer use one approach over another? Why might a designer want to be aware of his or her lens or another's lens? How might approaches affect outcomes? What actions might be different if you were using a different approach or lens? Only when students become aware of their own design tendencies and approaches and confront how they differ from others can they discern reasons for implementing different approaches. An awareness of different design lenses and ways to engage these different perspectives may be particularly important in cross-disciplinary collaborations (see Adams et al, 2010).

Engineering educators can also support students' awareness of their approaches and challenge them to employ different approaches by facilitating stopping points in the midst of design work. This does not mean telling engineering students what to do, but rather helping them chart their path of where they are, how they made decisions, and the implications of those decisions for where they want to go compared to what it would look like to utilize a different strategy at that point. This is a practice of structured self-reflection similar to the ideas posed earlier, but also includes challenging students in the process of designing to think about the existence of other approaches, why they chose particular approaches over others, and how choices enable different kinds of outcomes. Engineering educators could facilitate this conversation by drawing on the findings in this study as a way to help students imagine other kinds of approaches. Engineering students are often assumed to learn about design through experiences alone, without explicit conversations about approaches, processes, and big picture understandings (lenses) of what it means to experience and learn design. The act of thinking about a design experience "in action" or "on action" retrospectively 
(Adams et al, 2003; Schön, 1993), specifically reflecting on their decision-making, actions and strategies, and comparing it to the approaches of design practitioners, supports metacognition, facilitates improvements in design knowledge and skills, and supports development as a reflective practitioner.

While the outcomes of this study have implications for engineering education at all levels, they also have implications to disciplines outside of engineering. The implications of this work are as broad as the disciplines represented in the study background and design. The connections and relationships between an aspect considered central to engineeringdesign and work in other diverse disciplines helps us as engineers look beyond engineering to gain a more inclusive picture of design knowledge and skills. It also encourages us to look beyond our own discipline and develop a broader awareness that can improve our own practices, educational approaches, and bodies of knowledge.

\section{ConClusions}

In this study, phenomenographic techniques were used to understand the scope of awarenesses that designers have about the experience of designing, the variations that exist within this space in terms of critical components (categories of description), and the relationships among these variations. Here, design encompasses many disciplinary perspectives - those within engineering and those outside of engineering.

The theoretical implications of this study can contribute to a general theory of design that speaks specifically to engineering design, and theories of design learning and instruction. Practical implications include reflective practice and metacognition frameworks for engineering design education, with special attention on eliciting, connecting, and transferring prior conceptions of design to future design situations. There are also practical implications for collaborative and cross-disciplinary design in terms of making visible differences in design approaches that facilitate or inhibit common ground and pathways to innovation.

The findings from this study illustrate that there is much more to design than current definitions provide; design is also characterized by those who do it. Design has been defined and described both broadly and specifically, and while some work has included the perspective of the designer, there is still much to investigate with respect to how professional designers understand and approach design work. Investigations from this perspective expands not only how we understand and discuss design, but also how we educate and practice design.

Also evident from this work is that everyone does not experience design in the same way. While there are similarities in the nature of design among diverse disciplines, there are also critical variations in how individuals understand what it means to design (knowing) and how they go about design (doing). These critical variations have implications for bridging research on design knowing with design doing (processes, strategies, etc.), articulating features of design learning progressions, and revealing boundaries that may exist in cross-disciplinary collaborations. At the same time, there is much that holds designers across disciplines together. While the technical aspects of design work may vary significantly, there is common ground in the nature of design work that may be a crucial starting point for sharing cross-disciplinary approaches in engineering and education endeavors.

Experiences impact designers' lenses on design, which can impact their approaches to design scenarios. Awareness is key for designers of all skill levels - self-awareness of personal design lenses as well as awareness of other ways to view and approach design situations. 
Designers of all skill levels, novice to expert, have room to benefit from an increased awareness of their own lenses and approaches to design, based on the collection of their past design experiences, as well as other possible lenses and approaches to design work. Expanding awareness can result in new ideas, improved design skills, and innovative outcomes. It is our responsibility as engineering and design educators, engineering and design researchers, or engineers and designers to capitalize on what others have learned about design work and to strive to incorporate that learning into what it means to prepare engineers for their future role in society.

\section{ACKNOWLEDGMENTS}

The authors would like to thank Llewellyn Mann for his assistance, critical eye, and advice throughout the project.

\section{REFERENCES}

ABET Board of Directors. (2007). 2007-2008 Criteria for accrediting engineering programs. Retrieved from http://www.abet.org/forms.shtml

Adams, R. S., Turns, J., \& Atman, C. J. (2003). Educating effective engineering designers: The role of reflective practice. Design Studies, 24(3), 275-294.

Adams, R., Forin, T., Srinivasan, S., \& Mann, L.L. (2010). Cross-disciplinary practice in engineering contexts - a developmental phenomenographical perspective. In K. Gomez, L. Lyons and J. Radinsky (Eds.), Learning in the disciplines: Proceedings of the 9th International Conference of the Learning Sciences (ICLS) Volume 1, (pp. 1166-1173). Chicago, IL: International Society of the Learning Sciences.

Adams, R., \& Fralick, B. (2010). Work in progress: A conceptions of design instrument as an assessment tool. Proceedings of the Annual ASEE/IEEE Frontiers in Education Conference, Washington, DC.

Åkerlind, G. (2005). Learning about phenomenography: Interviewing, data analysis and the qualitative research paradigm. In J. A. Bowden \& P. Green (Eds.), Doing developmental phenomenography (pp. 63-73). Melbourne, Australia: RMIT University Press.

Åkerlind, G., Bowden, J., \& Green, P. (2005). Learning to do phenomenography: A reflective discussion. In J. A. Bowden \& P. Green (Eds.), Doing developmental phenomenography. Melbourne: RMIT University Press.

Akin, O., \& Lin, C. (1995). Design protocol data and novel design decisions. Design Studies, 16(2), 211-236.

Atman, C., Chimka, J., Bursic, K., \& Nachtmann, H. (1999). A comparison of freshman and senior engineering design processes. Design Studies, 20(2), 131-152.

Atman, C. J., Adams, R. S., Mosborg, S., Cardella, M. E., Turns, J., \& Saleem, J. (2007). Engineering design processes: A comparison of students and expert practitioners. Journal of Engineering Education, 96(4), 359-379.

Atman, C. J., Kilgore, D., \& McKenna, A. (2008). Characterizing design learning: A mixed-methods study of engineering designers' use of language. Journal of Engineering Education, 97(3), 309-329.

Ball, L., Ormerod, T., \& Morley, N. C. (2003). Spontaneous analogising in engineering design: A comparative analysis of experts and novices. Paper presented at the Design Thinking Research Symposium, DTRS6, Sydney, Australia. 
Bowden, J. (2000). The nature of phenomenographic research. In J. Bowden \& E. Walsh (Eds.), Phenomenography (pp. 1-18). Melbourne, Australia: RMIT University Press.

Bowden, J., \& Marton, F. (1998). The university of learning: Beyond quality and competence in higher education. London, UK: Cogan Page.

Brown, T. (2009). Change by design: How design thinking transforms organizations and inspires innovation. New York, NY: Harper Collins.

Bucciarelli, L. L. (1996). Designing engineers. Cambridge, MA: MIT Press.

Cardella, M. E., Atman, C. J., Adams, R. S., \& Turns, J. (2002). Engineering student design processes: Looking at evaluation practices across problems. Proceedings of the 2002 American Society for Engineering Education Annual Conference and Exposition, Montreal, Canada.

Cardella, M. E., Atman, C. J., Turns, J., \& Adams, R. S. (2008). Students with differing design processes as freshmen: Case studies on change. International Journal of Engineering Education, 24(2), 246-259.

Case, J., \& Light, G. (2011). Emerging methodologies in engineering education research. Journal of Engineering Education, 100(1), 186-210.

Christensen, B. T., \& Schunn, C. D. (2007). The relationship of analogical distance to analogical function and pre-inventive structure: The case of engineering design. Memory \& Cognition, 35(1), 29-38.

Clark, H. H., \& Brennan, S. A. (1991). Grounding in communication. In L. B. Resnick, J. M. Levine \& S. D. Teasley (Eds.), Perspectives on socially shared cognition (pp. 127-149). Washington, DC: APA Books.

Committee on Facilitating Interdisciplinary Research, National Academy of Sciences, National Academy of Engineering, \& Institute of Medicine. (2005). Facilitating interdisciplinary research. Washington, DC: National Academies Press.

Committee on the Engineer of 2020 Phase I. (2004). The engineer of 2020: Visions of engineering in the new century. Washington, DC: National Academy of Engineering.

Crismond, D., \& Adams, R. S. (in review). The informed design teaching and learning matrix. Submitted to the Journal of Engineering Education.

Cross, N. (1982). Designerly ways of knowing. Design Studies, 3(4), 221-227.

Cross, N. (1995). Discovering design ability. In R. Buchanan \& V. Margolis (Eds.), Discovering design: Explorations in design studies (pp. 105-120). Chicago, IL: University of Chicago Press.

Cross, N. (2001). Design cognition: Results from protocol and other empirical studies of design activity. In C. M. Eastman, W. M. McCracken \&W. C. Newstetter (Eds.), Design knowing and learning: Cognition in design education (pp. 79-104). Amsterdam, The Netherlands: Elsevier.

Cross, N. (2004). Expertise in design: An overview. Design Studies, 25(5), 427-441.

Cross, N. (2006). Designerly ways of knowing. London, UK: Springer-Verlag.

Cunningham, C. M., Knight, M. T., Carlsen, W. S., Kelly, G. (2007). Integrating engineering in middle and high school classrooms. International Journal of Engineering Education, 23(1), 3-8.

Dall'Alba, G. (2004). Understanding professional practice: Investigations before and after an educational programme. Studies in Higher Education, 29(6), 679-692.

Dall'Alba, G. (2005). Improving teaching: Enhancing ways of being university teachers. Higher Education Research ED Development, 24(4), 361-372.

Dall'Alba, G. (2009). Learning professional ways of being: Ambiguities of becoming. Educational Philosophy and Theory, 41(1), 34-45. 
Dorst, K. (2003). The problem of design problems. Paper presented at the Design Thinking Research Symposium, Sydney, Australia.

Douglas, J., Iverson, E. \& Kalyandurg, C. (2004). Engineering in the K-12 classroom: An analysis of current practices E guidelines for the future. Washington, DC: American Society for Engineering Education.

Dubberly, H. (2004). How do you design? Retrieved from http://www.dubberly.com/ articles/how-do-you-design.html.

Duderstadt, J. (2008). Engineering for a changing world: A roadmap to the future of engineering practice, research, and education. Ann Arbor, MI: The Millennium Project. Retrieved from http://milproj.dc.umich.edu/

Dym, C., Agogino, A., Eris, O., Frey, D., \& Leifer, L. (2005). Engineering design thinking, teaching, and learning. Journal of Engineering Education, 94(1), 103-120.

Eide, A., Jenison, R., Mashaw, L., \& Northup, L. (2002). Engineering: Fundamentals and problem solving. New York, NY: McGraw-Hill Companies Inc.

Engineers' Council for Professional Development. (1947). Canons of ethics for engineers. New York, NY: Engineers' Council for Professional Development.

Ertas, A., \& Jones, J. (1996). The engineering design process (2nd ed.). New York, NY: John Wiley \& Sons.

French, M. J. (1985). Conceptual design for engineers. London/ Berlin: The Design Council/ Springer.

Goel, V., \& Pirolli, P. (1992). The structure of design problem spaces. Cognitive Science, 16(3), 395-429.

Jonassen, D. (2000). Toward a design theory of problem solving. Educational Technology: Research Eं Development, 48(4), 63-85.

Jonassen, D. H., Strobel, J., \& Lee, C. B. (2006). Everyday problem solving in engineering: Lessons for engineering educators. Journal of Engineering Education, 95(2), 139-151.

Kabo, J., \& Baillie, C. (2009). Seeing through the lens of social justice: A threshold for engineering. European Journal of Engineering Education, 34(4), 317-325.

Kilgore, D., Atman, C. J., Yasuhara, K., Barker, T. J., \& Morozov, A. (2007). Considering context: A study of first-year engineering students. Journal of Engineering Education, 96(4), 321-334.

Lawson, B. (2006). How designers think: The design process demystified (4th ed.). Amsterdam, The Netherlands: Elsevier Press.

Lawson, B., \& Dorst, C. H. (2009). Design expertise. Oxford, England: Elsevier.

Lewis, K. E., Chen, W., \& Schmidt, L. C. (2006). Decision making in engineering design. New York, NY: American Society of Mechanical Engineers.

Leydens, J., Moskal, B., \& Pavelich, M. (2004). Qualitative methods used in the assessment of engineering education. Journal of Engineering Education, 93(1), 65-72.

Mann, L. (2007). Ways of experiencing sustainable design: A phenomenographic approach. (Doctoral dissertation). University of Queensland, Brisbane, Australia.

Marton, F. (1986). Phenomenography: A research approach investigating different understandings of reality. Journal of Thought, 21(2), 28-49.

Marton, F., \& Booth, S. (1997). Learning and awareness. Mahwwah, NJ: Lawrence Erlbaum Associates.

Marton, F., \& Tsui, A. B. M. (2004). Classroom discourse and the space oflearning. Mahwaw, NJ: Lawrence Erlbaum. 
Mehalik, M. M., \& Schunn, C. D. (2006). What constitutes good design? A review of empirical studies of the design process. International Journal of Engineering Education, 22(3), 519-532.

Mosborg, S., \& Adams, R. S. (2005). Investigating adaptive expertise. Presentation at the Adaptive Expertise Symposium, Stanford Research Institute, Palo Alto, CA.

Mosborg, S., Adams, R., Atman, C., Turns, J., Cardella, M., \& Kim, R. (2005). Conceptions of the engineering design process: An expert study of advanced practicing professionals. Proceedings of the 2005 American Society for Engineering Education Annual Conference and Exposition, Portland, Oregon.

National Academy of Engineering. (2004). The engineer of 2020: Visions of engineering in the new century. Washington, DC: National Academies Press.

National Academy of Engineering. (2011). National Academy of Engineering Website. Retrieved from http://www.nae.edu/nae/naehome.nsf/weblinks/NAEW-4NHME3? OpenDocument

Neely, L. (2007). Adaptive design expertise: A theory of design thinking and innovation. (Doctoral dissertation). Stanford University, Palo Alto, CA.

Nelson, H., \& Stolterman, E. (2003). The design way: Intentional change in an unpredictable world. Englewood Cliffs, NJ: Educational Technology Publications.

Newell, A., \& Simon, H. A. (1972). Human problem solving. Englewood Cliffs, NJ: Prentice-Hall.

Newstetter, W. C., \& McCracken, W. M. (2001). Novice conceptions of design: Implications for the design of learning environments. In C. M. Eastman, W. M. McCracken, \& W. C. Newstetter (Eds.), Design knowing and learning: Cognition in design education (pp. 63-78). New York, NY: Elsevier.

Pang, M. F. (2003). Two faces of variation-On continuity in the phenomenographic movement. Scandinavian Journal of Educational Research, 47(2), 145-156.

Petre, M. (2003). Disciplines of innovation in engineering design. Paper presented at the Design Thinking Research Symposium, Sydney, Australia.

Reid, A., \& Solomonides, I. (2007). Design students' experience of engagement and creativity. Art, Design E' Communication in Higher Education, 6(1), 27-39.

Rittel, H., \&Webber, M. (1973). Dilemmas in a general theory of planning. Policy Sciences, 4(2), 155-169.

Rowland, G. (2004). Shall we dance? A design epistemology for organizational learning and performance. Educational Technology Research and Development, 52(1), 33-48.

Sandberg, J. (1997). Are phenomenographic results reliable? Higher Education Research E。 Development, 16(2), 203-212.

Schön, D. A. (1993). The reflective practitioner: How professionals think in action. New York, NY: Basic Books.

Sheppard, S., Macatangay, K., Colby, A., \& Sullivan, W. (2009). Educating engineers. Design for the future of the field. San Francisco, CA: Jossey-Bass.

Simon, H. A. (1969). The sciences of the artificial. Cambridge, MA: MIT Press.

Stacey, M., Eckert, C., \& Earl, C. (2009). From ronchamp by sledge: On the pragmatics of object references. In J. McDonnell \& P. Lloyd (Eds.), About: Designing - analysing design meetings (pp. 360-379). London, UK: Taylor and Francis Group.

Thomas, J. C., \& Carroll, J. M. (1979). The psychological study of design. Design Studies, 1(1), 5-11. 
Trigwell, K. (2000). A phenomenographic interview on phenomenography. In J. Bowden \&E. Walsh (Eds.), Phenomenography (pp. 62-82). Melbourne, Australia: RMIT University Press.

Tuckman, B. (1965). Developmental sequence in small groups. Psychological Bulletin, 63(6), 384-399.

Valkenburg, R. (1998). The reflective practice of design teams. Design Studies, 19(3), 249-271.

Visser, W. (2006). The cognitive artifacts of designing. Mahwwah, NJ: Lawrence Erlbaum.

Vredenburg, K. (2003). Building ease of use into the IBM user experience. IBM Systems Journal, 42(4), 517-531.

Winograd, T. (1996). Bringing design to software. Reading, PA: Addison-Wesley.

Zimring, C., \& Craig, D. L. (2001). Defining design between domains: An argument for design research á la carte. In C. M. Eastman, W. M. McCracken \& W. C. Newstetter (Eds.), Design learning and knowing: Cognition in design education (pp. 125-146). New York, NY: Elsevier Press.

Zoltowski, C. B., Oakes, W. C., Cardella, M. E. (2012). Students' ways of experiencing human-centered design. Journal of Engineering Education, 101(1), 21-59.

\section{AUTHORS}

Shanna R. Daly is an assistant research scientist in Engineering Education at the University of Michigan, 210 Gorgooze Family Laboratory, 2609 Draper Road, Ann Arbor, MI, 48104; srdaly@umich.edu.

Robin S. Adams is an associate professor in the School of Engineering Education at Purdue University, 1233 Armstrong Hall, 701 West Stadium Ave., West Lafayette, IN 47907-2045; rsadams@purdue.edu.

George M. Bodner is the Arthur E. Kelly Distinguished Professor of Chemistry, Education and Engineering, where he has been head of the Division of Chemical Education and a member of the faculty of the School of Engineering Education, Purdue University, 560 Oval Drive, West Lafayette, IN, 47907; gmbodner@purdue.edu. 